\title{
Epidemiological Value of Continuity of Care in General Medicine (Part Two)
}

\section{Turabian JL*}

Specialist in Family and Community Medicin, Health Center Santa Maria de Benquerencia, Spain

*Corresponding author: Jose Luis Turabian, Health Center Santa Maria de Benquerencia, Toledo, Spain, Email: jturabianf@hotmail.com

\section{Review Article \\ Volume 4 Issue 1}

Received Date: January 20, 2020

Published Date: February 19, 2020

DOI: $10.23880 /$ eij-16000138

\section{Abstract}

For most illnesses the general practitioner (GP) is the first point of contact in the health care system. He/she looks after a population whose age and sex composition is known. The continuity of care in general medicine -the relationship that is established in the long term between the GP and the patients in his/her office- has positive effects from the epidemiological point of view. The continuity of care allows to the doctor to see repeated patterns of events and trends or regularities through generations, family functioning and its relationship to events, family structure, coalitions between members, the family rules, myths, rituals, etc. But there is a gap for GPs on continuity of care in regard to its epidemiological implications that are not even taken into consideration. This article, second part of two, pretend to reflect, on some of the fundamental epidemiological elements that are provided by continuity of care in general medicine, and its practical applications: 4 . Community diagnosis: a continuous process, along with planning, decision making and implementation of intervention programs; 5. Knowledge of the natural history of the disease: general medicine presents a unique opportunity to study the natural history of disease and the GP work includes the natural history of disease and the human life cycle, and so, no one is better able to observe, from the family history, the ultimate consequences of any health problem; 6. Obtaining epidemiological hypotheses: continuity of care allows the identification of epidemiological hypotheses to be tested later; 7 . The possibilities of epidemiological studies from the data of continuity of care: case studies, multiple case studies, longitudinal studies (prospective and retrospective), cohort studies, seasonal variations, and qualitative studies. The GPs can make a significant contribution to the epidemiological research of diseases on the basis of patients seen in routine practice over time.

Keywords: Continuity of care; Epidemiology; Community medicine; General practitioner; Disease; Diagnosis

\section{Introduction}

The relationship that is established in the long term between general practitioner (GP) and the patients in his office is considered to be "continuity of care." The continuity of care can be defined as [1-3]:

1. Attention by the same doctor, throughout life, of most of the patient's problems.

2. The recognition that the knowledge of the population and patients is a source of care that is available for the diagnosis and monitoring of problems.

GPs offer continuity; that is, they offer the followup of specific health problems and the follow-up of the 


\section{Epidemiology International Journal}

person with the set of health problems that will affect him throughout his life. The benefits of continuity are multiple, from the decrease in patient mortality to the decrease in health system costs, including important opportunities for epidemiological knowledge of health problems. Continuity of care between the doctor and the patient builds trust and allows the physician to use more productively the time available $[4,5]$.

The concept of continuity of care involves the meaning of medical attention over time. "Time is a fluid." Thus, it is often said that "life is like a river"; now, at what speed does a river move? The slope and the path accelerate or slow down the current. The truth is that two drops of water thrown at once from the birth of a river never reach the sea at the same time. In a straight channel, the water that moves faster is the one in the center, just below the surface. The minimum water speed is found on the banks and in the riverbed. In a tortuous channel, on the other hand, the maximum speed is reached outside each curve; in the riverbed, in the deepest part, the water is moving so slowly that it could remain still. It may be impossible to track the movement of each individual molecule in a fluid, but uncertainty and disorder at the molecular level disappear when the overall picture is observed. This metaphor points to the importance of observing the big picture through ongoing collection of data over time. Similarly, regularities arise from individually unpredictable situations. Continuity of care brings us closer to this knowledge. Statisticians and epidemiologists have travelled a route toward maximum certainty in an uncertain world. In this way we can ask ourselves, for example, how many patient deaths are too many during a certain time? "In this process of studying events over time, powerful ideas have emerged to form the basis of modern scientific research $[6,7]$.

Despite professional recognition of the importance of continuity of care, there is little practical guidance for general practitioners [8]. In addition, this lack of assessment of continuity of care is even greater in terms of its epidemiological implications that are not even taken into consideration by both GPs and epidemiologists.

In this scenario, this article, second part of a previous one [9], and based on a chosen narrative review and the author's own experience, aims to reflect and conceptualize the fundamental epidemiological elements that provide the continuity of care in general medicine, and its practical applications.

\section{Methods}

The comments in this article should be considered as a personal point of view, based on the author's experience during 30 years of work in general medicine, plus an unsystematic or opportunistic search for information.

The search for information was based on a nonsystematic review considering the bibliographic references of selected articles, reviews of books related to the topic and opportunistic searches on the Internet.

This non-systematic review was carried out, which aimed to explore, describe and discuss the topic of continuity of care in general medicine, in a broad way, considering multiple factors from a theoretical and contextual point of view; that is, observing the subject in all its possible implications (organizational, management, clinical, community, statistics) and its impact on epidemiology.

A personal point of view, or personal opinion was used, that is, the position, consideration, attitude, and opinion that the author adopts, on the fact of continuity of care in general medicine. Therefore, this personal point of view to get the information and to analyze it, is subject to the subjectivity of the author. But, in trying to achieve a broad and contextualized perspective, it is intended to minimize this subjectivity of the personal gaze or focus on the subject: on the one hand by triangulating personal experience with the non-systematic bibliographic information obtained, and on the other hand, by contextualizing or focusing comments on a context of national health system, universal and free, in Europe, where the GP acts as a gatekeeper of the health system, and all people have a GP, which is the context of the author.

In the firstpart of this article the following epidemiological elements that are provided by continuity of care in general medicine were discussed: 1. Epidemiological efficiency of continuity of care (application of Bayes' theorem): it allows to evaluate at very low cost previous probabilities and increases the pretest probability; 2 . Continuity of registration: a registry of patients with a specific disease can be useful not only as a basis for the calculation of prevalence or incidence rates, but also as a tool to ensure that certain patients receive the care they need; And 3. Knowledge of numerators and denominators: it allows knowing the beginning or incidence of health problems; the beginning of preventive interventions (case finding); to know the prevalence; knowing the associated factors that may suggest causality; knowing the prognosis; knowing the evolution of the health problem (intermittent course, persistent course, worsening, evolution of the severity of symptoms, exacerbations, complications; etc.); knowing the process or trajectory of accumulation of diseases in people throughout life, and the factors associated with this phenomenon. 


\section{Epidemiology International Journal}

\section{Discussion}

An important characteristic of $\mathrm{GP}^{\prime}$ medical care, in the community, is its continuity for long periods of time. This builds a special relationship between GPs, patients and their families. GPs that get to know several members of the same family in the course of their practice, and as such, are better able to use this knowledge of the family's health status, its resources, relationships and their perception of health, when family members turn to them for diagnosis and treatment [10].

\section{"Déjà vu"}

Continuity of care produces a kind of "Déjà vu" phenomenon in the GP. It is the phenomenon of having the strong feeling that an event or experience that is lived today has been experienced in the past. The GP, based on the continuity of care, often feels that situation of "Déjà vu": "that clinical picture already seen previously in that patient"..., "and this disease which improved with that treatment in this patient..." Thus, the GP can reach the diagnosis in a few minutes, and he/she can almost predict the patient's reason for consulting "in a magical way", before the patient enters the consultation, based on his knowledge of this person and the course of tens of previous consultations ("the GP had already been and he/she had seen that before in that patient in those circumstances"). Life goes as in a circle, and when the GP encounters new situations, you may feel that it has happened before.

The population disease is a dynamic and cyclical process, so for its interpretation it is necessary not only to know, but also to apply an epidemiological approach [11]. This epidemiological approach or value of continuing care can be classified into a series of concepts which are showed in Table 1. In this second part, points 4 to 7 of this Table 1 will be briefly commented:

\begin{tabular}{|l|l|}
\hline \multicolumn{2}{|c|}{ Some Epidemiological Concepts that can be Developed from the Continuity of Care Approach } \\
\hline 1 & Epidemiological efficiency of continuity of care (application of Bayes' theorem) \\
\hline 2 & Continued registration (the medical record in continuity of care) \\
\hline 3 & Knowledge of numerators and denominators \\
\hline 4 & Community diagnosis \\
\hline 5 & Knowledge of the natural history of the disease \\
\hline 6 & Develop epidemiological hypotheses \\
\hline 7 & The possibilities of epidemiological studies from the data of continuity of care \\
\hline
\end{tabular}

Table 1: Some Epidemiological Concepts that can be developed from the continuity of care approach.

\section{Community Diagnosis}

The community diagnostic process may be related to a broad spectrum of scenaries, for example, a community health syndrome that involves a number of disorders and their causal factors and effects, or it can be reduced to a very specific problem. It may include the identification of highrisk groups or other groups that require special attention.

Community diagnosis is a continuous process, along with planning, decision making and implementation of intervention programs. As the health status of a community changes, the determinants of these changes also change, therefore, the diagnosis of the community changes. This requires continuous monitoring of health in the community: the early diagnosis of particular health conditions in the community will be followed by integrated routines in the practice, and that allows health surveillance of these conditions and their determinants [12].

\section{Knowledge of the Natural History of the Disease}

General medicine is a major source of information about health problems and their evolution. For most illnesses GP is the first point of contact in the health care system by looking after a population whose age and sex composition is known. He/she is therefore in an ideal position to conduct inquiries about the natural history of disease (i.e., factors predisposing, precipitating and perpetuating the disease). The essence of general medicine is to assist individuals in families and communities, and this implies a good continuity of care, and moreover a knowledge of the nature of diseases over time in the community [13].

General medicine presents a unique opportunity to study the natural history of disease and allows the establishment of patient-physician-family-community relationships. The GP work includes the natural history of disease and the human life cycle, and so, no one is better able to observe, from family history, the ultimate consequences of any health problem 


\section{Epidemiology International Journal}

$[14-16]$

One priority object of medical studies should be the knowledge of the natural history of the disease. Ignorance of this evolution can lead to significant errors of judgment on the therapeutic indications. Knowing the evolutionary trend of the disease, the GP and epidemiologist can do a classification of diseases according to their pattern of natural history. Different diseases affect people at different ages and their course and results differ. Five patterns of the natural history of diseases can be described [13]:

A. The common disease pattern in children. For example: catarrhal syndrome, umbilical hernia, nevus "strawberry", growing pains, enuresis, etc. They have high incidence and prevalence during a plateau and a descent to a level of low incidence that is maintained.

B. Many diseases become more prevalent with age and some become serious. For example: osteoarthritis, coronary heart disease, stroke, peripheral arteriopathy, hypertension, COPD and cancers. There is a plateau of low incidence and prevalence, followed by an increase from the average age of life to a plateau of high prevalence and incidence.

C. Some diseases are "once and always". That is, once they arise, they persist during all their lives. Example: some congenital diseases such as Down syndrome and cystic fibrosis, and acquired diseases such as diabetes, hypothyroidism, blindness and deafness. They present a constant plateau of prevalence and incidence.

D. Some diseases appear to follow a course and disappear: they tend to appear early in the middle of adulthood. There is a period of clinical activity, persistent or intermittent, that can last 10-20 years and then the symptoms decrease or disappear. Examples: asthma, migraine, allergic rhinitis, low back pain, duodenal ulcer, anxiety, depression, urinary tract infections in women, and various gynecological problems.

E. Some diseases with high prevalence and incidence in young and old. They include bronchial hyperreactivity, hydrocele, hernias and constipation.

The GP is not only involved in trying to move the person toward health, but also acts as a witness to the patient experience. The GP is the professional prepared to observe what happens over time, to inform and even think about it; he or she is someone prepared to leave aside prejudices and assumptions, and to see what really happens, not just what biomedicine can expect to happen.

The continuity of care allows the doctor to see repeated patterns of events and trends or regularities through generations, family functioning and its relationship to events, family structure, coalitions between members, the family rules, myths, rituals, etc.

It allows the GP to see patterns beneath the apparent diversity of reasons for consultation; It facilitates the diagnosis and treatment, monitoring of the chronically ill, the implementation of preventive elements, and improves patient satisfaction. The evolution in humans is not a linear process or progressive of accumulation, but a dialectical process in which the crisis of life always impose us a while to back and another forward: health problems improve, disappear, reappear, accumulate, intersect, are associated and/or diverge over time [17-19].

\section{Developing Epidemiological Hypotheses}

Continuity of care allows the development of epidemiological hypotheses to be tested later, such as:

-The pattern of transmission of certain infectious diseases among nearby people, such as influenza, common cold, infectious gastroenteritis, keratoconjunctivitis [20] and transmission of diseases with genetic basis [21].

-The efficacy or poor efficacy of certain drugs, such as antidepressants, and the frequency of their adverse effects (in the example of antidepressants, the change of thoughts, feelings and behaviours giving rise to a situation of passivity, difficulty in taking decisions, difficulty understanding the problem surrounding the patient, etc., generating a structuring of symptoms).

-The observation of community syndromes, so that certain diseases tend to be associated in certain patients and contexts [22].

\section{The Possibilities of Epidemiological Studies from the Data of Continuity of Care}

Case studies: In this design the natural history of the disease is studied, describing the "clinical experience". For example, case studies of adverse drug reactions are simple and inexpensive to develop in outpatient settings, although it must be remembered that a biased selection of patients can lead to errors of interpretation [23-25].

Multiple case studies: Multiple case studies pursue the development and contrast of certain explanations in a representative framework of a more general context, and aim to generate theory by contrasting the hypotheses within diverse contexts. In this sense, they can be especially useful, For example, the study of the natural history of the accumulation of diseases, propose a new theory: the 


\section{Epidemiology International Journal}

multimorbidity, in a small but significant part, is created by the medical intervention itself [26].

One of the main biases associated with case studies is that their conclusions are not statistically generalizable [27]. However, what can be generalized are the theoretical propositions, since the objective of the researcher is to understand the interaction between the different parts of a system and the important characteristics of the system, in such a way that the analysis carried out can be applied in a generic way, expanding and generalizing theories (analytical generalization) and not enumerating frequencies (statistical generalization) [28].

Longitudinal studies (prospective and retrospectives): Most research on health has taken a cross-sectional approach to the study of the population. Relationship betweenindividual and population health is largely relative and dynamic. Their interrelated dynamism derives from a causally defined life course perspective on health determination starting from an individual's conception through growth, development and participation in the collective till death, all seen within the context of an adaptive society.

Longitudinal studies are required to explore the factors that produce or lead to multi-morbidity, and in particular to determine how in a person or family to which a first disease is diagnosed, others are added along the continuum of life, to allow the design of individualized preventive strategies.

So, qualitative and quantitative longitudinal studies, in persons, families and populations, are needed to identify not only the types or patterns of diseases groupings -over what has been described a lot of literature-, but especially about the trajectory of the causal chain of accumulation of health problems [29].

Longitudinal studies are of sufficient complexity to require, not only a multidisciplinary team to address them but also a sufficient amount of resources to maintain them over time. However, the characteristic of the continuity of care in general medicine implies a logistical and economic advantage to be able to carry out this type of study, since it can be included in the characteristic of "longitudinality" of care.

Cohort Studies: This design allows identification of the early-life predictors of long-term multi-morbidity (historical cohort). For example, the hypothesis that children who experience more illnesses at a young age may be prone to develop multi-morbidity in later life [30] can be assessed. Also, for example, this design allows to evaluating hypotheses about timing of onset and self-management of multiple chronic conditions taking a lifespan perspective [31].
Likewise, to studying health transitions over the life course: there seem to be individuals or families', where historical events, life experiences, and formal and informal support may have led to be a "troubled family" [32].

Seasonal Variations: It has long been accepted that morbidity patterns in general practice vary seasonally, which depends on the acute pathology of infectious origin, mainly of respiratory infections. General medicine is a major source of information about health problems and their variation $[33,34]$.

Qualitative studies: In recent years qualitative research has been recognized as making a valuable contribution to medical science. The growing popularity of qualitative research is fuelled in part by the realization that traditional quantitative research is limited in its ability to capture the meanings people attach to health care social phenomena, and that qualitative research is necessary to understand the experiential and interpretive elements of medical practice. This research is capable of enhancing clinical knowledge and care. As more people recognize the unique benefits of qualitative research, its popularity will continue to grow in the health sciences.

An attentive look at the day-to-day activities of GPs shows the great similarities between qualitative research and the practice of general medicine. The experience of being a GP is similar to the experience of being an ethnographer who conducts a qualitative study: the GP remains in a same consultation for a long time, developing relationships with patients and their contexts, and understanding their visions and knowledge, so that he/she can better interprets the signs and symptoms of someone disease. In the consultation, the GP as an ethnographer conducts an interview with a patient, for which he/she needs to establish a tune and also tries to understand and interpret the patient's perspective and experience, feelings and values. As an ethnographer, the GP must interact with a wide variety of people, many of whom have different ways of understanding reality, previous stories and life experiences. Both the GP and the ethnographer negotiate their relationships with these different people to minimize the barriers of understanding. But unlike the ethnographer, the GP is practice-oriented, and should treat each patient not only observe $[35,36]$.

\section{Conclusion}

For most illnesses the GP is the first point of contact in the health care system and he/she looks after a population whose age and sex composition is known. The continuity of care in general medicine has positive effects from the epidemiological point of view. Epidemiological investigations in general medicine practices allow the analysis of the data 


\section{Epidemiology International Journal}

to determine, at least, the health priorities on which the practice should focus, and the most intensive epidemiological research through various possibilities of study designs. GPs and epidemiologists should recognize the importance of the continuity of the relationship and care, and should play a more active role making it possible to obtain epidemiological results from it.

In epidemiological investigations in general medicine practices, the knowledge that the professional accumulates about the community, and the use of social and behavioral variables, together with the clinical data, must be commonly used in clinical and epidemiological studies. A continued knowledge of the community affiliated to the general medicine practice, which is a reflection of the general community, and of its people is as important for the successful work of general medicine, as for public health and for epidemiology. The GP can make a significant contribution to epidemiological research of diseases on the basis of patients seen in routine practice over time

\section{References}

1. Castiel LD, Álvarez Dardet C (2007) Persecutory health. Rev Saúde Pública 41(3).

2. White ES, Gray DP, Langley P, Evans PH (2016) Fifty years of longitudinal continuity in general practice: a retrospective observational study. Fam Pract 33(2): 148153.

3. Gérvas J, Ortún V (1995) Characterization of the general/ family doctor's assistance work. Aten Primaria 16 (8): 501-506.

4. Anonymous (2019) The benefits of longitudinality and continuity. FoCAP.

5. Turabian JL (2018) Doctor-Patient Relationship Epidemiology and its Implications on Public Health. Epidemol Int J 2(3): 1-6.

6. Turabian JL (2017) Stories Notebook about the Fundamental Concepts in Family Medicine: Continuity, The Fable of The River with Meanders. J Gen Pract (Los Angel) 5: 285.

7. Fry H (2019) What Statistics Can and Can't Tell Us About Ourselves. The New Yorker.

8. Freeman G, Hughes J (2010) Continuity of care and the patient experience. An Inquiry into the Quality of General Practice in England. The King's Fund.

9. Turabian JL (2020) Epidemiological Value of Continuity of Care in General Medicine (Part one of Two) Epidemol
Int J 4(1): 1-6.

10. Turabian JL (2018) The General Physician along the Patients 'High and Low Tides'. Journal of Public Health and General Medicine 1(1): 1-3.

11. Valdivia Onega NC (2003) Epidemiology and primary health care. Rev Cubana Hig Epidemiol 41(2-3).

12. Abramson JH, Kark SL (1983) Community Oriented Primary Care: Meaning and Scope. Community Oriented Primary Care: New Directions for Health Services Delivery. Institute of Medicine (US) Division of Health Care Services; Connor E, Mullan F, editors. Washington (DC).

13. Turabian JL (2017) A Narrative Review of Natural History of Diseases and Continuity of Care in Family Medicine. Arch Community. Med Public Health 3(1): 041-047.

14. Morrell D (1991) The art of general practice. Oxford: Oxford University Press.

15. Freeman GK, Olesen F, Hjortdahl P (2003) Continuity of care: an essential element of modern general practice? Fam Pract 20(6): 623-627.

16. Woo B (2006) Primary Care - The Best Job in Medicine? N Engl J Med 355: 864-866.

17. Turabian JL (2017) Fables of Family Medicine. A collection of fables that teach the Principles of Family Medicine. Saarbrücken, Deutschland/Germany: Editorial Académica Española.

18. Turabian JL, Perez Franco B (2015) Observations, insights and anecdotes from the perspective of the physician, for a theory of the natural history of interpersonal continuity. The colors of time. Rev Clin Med Fam 8(2).

19. Turabián JL, Samarín-Ocampo E, Minier L, Pérez-Franco B (2015) Learning concepts of diagnosis in family medicine: the "mark robinson sign" - the traces that should not be there. Aten Primaria 47(9): 596-602.

20. Turabian JL (2017) A Large Family outbreak of Keratoconjunctivitis in General Practice: Specific Epidemiological Implications in Family Medicine. J Community Med Public Health: CMPH-110.

21. Turabian JL (2017) The Importance of the Family Approach in General Medicine: An Induction and Review of Concepts from a Case of Hereditary Renal Disease. Chronicle of Medicine and Surgery 1(1): 18-30.

22. Turabián Fernández JL, Baltuille Aller C, Rodríguez Alcalá J, Velasco Llaves B, García Alvarez C, et al. (1997) 


\section{Epidemiology International Journal}

Community syndromes as a method of classifying patients in family medicine. Revista de Medicina Familiar y Comunitaria 7(3): 154-159.

23. Díaz De Salas SA, Mendoza Martínez VM, Porras Morales CM ( 2011) A guide for the development of case studie. Razón Y Palabra 75.

24. Castro Monge E (2010) El estudio de casos como metodología de investigación y su importancia en la dirección y administración de empresas. Revista Nacional de administración 1(2): 31-54.

25. Stoppiello LA (2009) A single case study: issues in the sample selection of a doctoral thesis research. Subj Procesos Cogn 13(2).

26. Jose Luis Turabian (2018) Longitudinal Study of a Series of Cases on Trajectory of the Chain of Accumulating Health Problems in Certain People. Am J Family Med 1(1): 1001.

27. Yin RK (2004) case study methods. COSMOS Corporation Revised Draft

28. Violán C, Foguet-Boreu Q, Roso-Llorach A, RodriguezBlanco T, Pons-Vigués M, et al. (2016) Multimorbidity patterns in young adults in Catalonia: an analysis of clusters. Aten Primaria 48 (7): 479-492.

29. Arah OA (2009) On the relationship between individual and population health. Med Health Care Philos 12(3): 235-244.

30. Humphreys J, Jameson K, Cooper C, Dennison E (2018)
Early-life predictors of future multi-morbidity: results from the Hertfordshire Cohort. Age Ageing 47(3): 474478.

31. Koyanagi A, Köhler-Forsberg O, Benros ME, Munk Laursen T, Haro JM, et al. (2018) Mortality in unipolar depression preceding and following chronic somatic diseases. Acta Psychiatr Scand 138(6): 500-508.

32. Gustafsson PE, Hammarström A, San Sebastian M (2015) Cumulative contextual and individual disadvantages over the life course and adult functional somatic symptoms in Sweden. Eur J Public Health 25(4): 592-597.

33. Turabian JL (2017) The Variation of Seasonal Diseases in Family Medicine Depends on Infectious Diseases and these are Mainly Respiratory Diseases. J Gen Pract (Los Angel) 5: 309 .

34. Turabian JL, Cucho-Jove R, Moreno-Ruiz S (2017) Conceptual Implications of Family Medicine in the Study of the Seasonal Variation of Diseases: A Narrative Review. CP Epidemiology 1(1): 001.

35. Báez-Montiel BB, Gutiérrez-Islas E, Bolaños-Maldonado M, Samarín E, Turabián JL (2014) The odysseys of Ulysses. A study of tales in a normal working day of the family doctor in Paraguay, Mexico, Peru, and Spain. Aten Primaria 46: 68-76.

36. Scheffelaar A, Hendriks M, Bos N, Luijkx K, Van Dulmen S (2019) Determinants of the quality of care relationships in long-term care - a participatory study. BMC Health Services Research 19: 389. 